\title{
The Quest to Conquer the Maternal Postprandial Glucose Concentration
}

\author{
Lois Jovanovič* \\ Clinical Professor of Medicine, University of Southern California, USA
}

*Corresponding author: Lois Jovanovič, Clinical Professor of Medicine, University of Southern California, USA

Submission: 海January 19, 2018; Published: 㭗January 22, 2018

\section{Opinion}

Once upon a time, I had the task of analyzing the glucose diaries of 322 type 1 diabetic women who performed 8-10 self-monitored blood glucose tests a day for at least 14 days before conception and throughout pregnancy including labor and delivery and a month postpartum [1]. I always thought that maternal hyperglycemia was the villain that caused malformations and macrosomia, but there was no concrete evidence that glucose was the main culprit [2]. I spent hours poring over the data and all of a sudden the answer appeared: the highest blood glucose of the day, not the average or the pre-prandial glucose, related to macrosomia. I asked the statistician to confirm my crude observation and thus the landmark paper was published in 1991 and validated my observation [3].

The twist to the results was that the highest blood glucose of the day was one hour (not two hours) after the start of the meal. This observation was contrary to the ADA's guidelines for care stated that the postprandial glucose was to be measure at the two hour postprandial time point [4]. The experts on this statement were concerned about hypoglycemia from the pre-prandially injected insulin .this group of experts defined the word postprandialas the plasma glucose concentrations after eating but stated that many factors determine the postprandial glucose profile. They reported that in non-diabetic individuals, fasting plasma glucose concentrations (i.e., following an overnight 8- to 10-h fast) generally range from 70 to $110 \mathrm{mg} / \mathrm{dl}$. Glucose concentrations begin to raise $\sim 10$ min after the start of a meal as a result of the absorption of dietary carbohydrates. They concluded that the postprandial profile is determined by carbohydrate absorption, insulin and glucagon secretion, and their coordinated effects on glucose metabolism in the liver and peripheral tissues.

They also stated that the magnitude and time of the peak plasma glucose concentration depend on a variety of factors, including the timing, quantity, and composition of the meal. In non-diabetic individuals, plasma glucose concentrations peak $\sim 60 \mathrm{~min}$ after the start of a meal, rarely exceed $140 \mathrm{mg} / \mathrm{dl}$, and return to preprandial levels within 2-3h. Even though glucose concentrations have returned to preprandial levels by $3 \mathrm{~h}$, absorption of the ingested carbohydrate continues for at least 5-6h after a meal. Because the absorption of food persists for 5-6h after a meal in both diabetic and non-diabetic individuals, they concluded that the optimal time to measure the postprandial glucose concentration is two hours after the start of a meal. Thus the highest blood glucose of the day (the one hour postprandial) would not be detected. Many times I have been told by clinicians that they have patients who had "normoglycemia" throughout pregnancy but had a macrosomic infant anyway. Obviously they did not know that their patients had postprandial hyperglycemia.

The only means to maintaining the one hour postprandial glucose in the normal range (less than $120 \mathrm{mg} / \mathrm{dl}$ ) is to decrease the carbohydrate content of the meal $[5,6]$. Here too I was fighting the philosophy that fats are bad and thus the carbohydrate content of meal plan needs to be greater than $50 \%$ to achieve adequate caloric intake [6]. My next plunge into reams of data was to analyze the diet diaries to study the highest amount of carbohydrate a pregnant woman can consume without producing a peak postprandial response about $120 \mathrm{mg} / \mathrm{dl}$. The result was a meal plan consisting of less than 33\% carbohydrate. However, breakfast must be almost devoid of carbohydrate in order to achieve a normal postprandial glucose concentration. The diurnal variation of hormones is potentiated in pregnancy. The morning cortisol level in pregnancy creates severe glucose intolerance. This observation resulted in the birth of the "Euglycemia Diet" in pregnancy [7].

My next major endeavor was the study of the safety and efficacy of rapid- acting insulin analogues. These insulin analogues were developed to shorten the lag-time between injection and peak insulin levels. The concentration of insulin at the one hourtime point allows for the opportunity to ingest more carbohydrate without producing postprandial hyperglycemia. The two rapidacting insulin analogues that prevent postprandial hyperglycemia are (and are considered category B in pregnancy) are insulin lispro and insulin aspart [8-12].

It is well known that exercise before eating results in a lower postprandial glucose concentration [10]. However, exercise was not recommended during pregnancy [11]. Thus I next studied 5 different types of exercise while the fetus was monitored. Arm 
ergometry emerged as the safest form of exercise for pregnant women and resulted in no uterine irritability, no fetal distress and lowered the postprandial glucose concentration by $30 \mathrm{mg} / \mathrm{dl}[13-$ 15].

Lastly, I had the opportunity to study the optimal glucose concentration during labor and deliver [16]. Here I utilized the glucose controlled insulin delivery device called the biostatorto observe the optimal glucose and insulin infusion rates during labor and delivery. I assumed that labor was stress and thus the insulin requirement during labor and delivery would be increased above that in resting state. However, it was clear that the exercise of a contracting uterus decreased the maternal glucose concentration. The insulin requirement during labor and delivery was decreased, whereas the glucose in fusion rate needed to be increased to $2.55 \mathrm{mg} / \mathrm{kg}$ per hour; equal to the glucose need of a trained marathon runner [17].

In summary, my quest to conquer the postprandial glucose concentration lead to an entire career of developing the safest means to achieve and maintain normoglycemia before, during and after all pregnancies complicated by diabetes [18].

\section{References}

1. Jovanovič L, Peterson CM, Reed GF, Metzger BE, Mills JL, et al. (1991) Maternal postprandial glucose levels and infant birth weight: the diabetes in early pregnancy study. The National Institute of Child Health and Human Development --Diabetes in Early Pregnancy Study. Am J Obstet Gynecol 164 (1 Pt 1): 103-111.

2. Jovanovič L, Peterson CM, Saxena BB, Dawood MY, Saudek CD (1980) Feasibility of maintaining euglycemia in insulin-dependent diabetic women. Am J Med 68: 105-112.

3. Jovanovič L, Singh M, Saxena BB, Mills JL, Tulchinsky D, et al. (1987) Verification of early pregnancy tests in a multicenter trial. Proc Soc Exper Biol Med 184(2): 201-205.

4. Professional Practice Committee for the Standards of Medical Care in Diabetes-2015. Diabetes Care 38 (Supplement 1): S88-S89.

5. Peterson CM, Jovanovič L (1991) Percentage of carbohydrate and glycemia response to breakfast, lunch, and dinner in women with gestational diabetes. Diabetes 40 (Suppl 2): 172-174.
6. Jovanovič L (2008) Using meal-based self-monitoring of blood glucose as a tool to improve outcomes in pregnancy complicated by diabetes. Endocr Pract 14(2): 239-247.

7. Jovanovič L, Bevier W, Peterson CM (1997) The Santa Barbara County Health Care Services Program: birth weight change concomitant with screening for and treatment of glucose-intolerance of pregnancy: a potential cost-effective intervention. Am J Perinatol 14(4): 221-228.

8. Jovanovič L, Ilic S, Pettitt DJ, Hugo K, Gutierrez M, Bowsher RR, Bastyr EJ (1999) Metabolic and immunologic effects of insulin lispro in gestational diabetes. Diabetes Care 22(9): 1422-1427.

9. Pettitt DJ, Ospina P, Kolaczynski JW, Jovanovič L (2003) Comparison of an insulin analog, insulin aspart, and regular human insulin with no insulin in gestational diabetes mellitus. Diabetes Care 26(1): 183-186.

10. Wyatt JW, Frias JL, Hoyme HE, Jovanovič L, Kaaja R, et al. (2004) Congenital anomaly rate in offspring of pre-gestational diabetic women treated with insulin lispro during pregnancy. Diabetic Medicine 21: 2001-2007.

11. Pettitt DJ, Ospina P, Howard C, Zisser H, Jovanovič L (2007) Efficacy, Safety and lack of immunogenicity of insulin aspart compared to regular human insulin for women with gestational diabetes mellitus. Diabet Med 24(10): 1129-1135.

12. Durak EP, Jovanovič L, Peterson, CM (1990) Comparative evaluation of five aerobic machines and their effect on uterine activity during pregnancy. Am J ObstetGynecol 162(3): 754-756.

13. Jovanovič L, Kessler A, Peterson CM (1985) Human maternal and fetal response to graded exercise. J Appl Physiol 58(5): 1719-1722.

14. Jovanovič L, Durak EP, Peterson CM (1989) Randomized trial of diet versus diet plus cardiovascular conditioning on glucose levels in gestational diabetes. Am J Obstet Gynecol 161(2): 415-419.

15. Jovanovič L, Peterson CM (1991) Is exercise safe or useful for gestational diabetic women? Diabetes 40(Suppl 2): 179-181.

16. Jovanovič L, Peterson CM (1983) Insulin and glucose requirements during the first stage of labor in insulin-dependent diabetic women. Am J Med 75(4): 607-612.

17. Jovanovič L (2004) Glucose and insulin requirements during labor and delivery: the case for normoglycemia in pregnancies complicated by diabetes. Endocrine Practice 10(Suppl 2): 40-45.

18. Blumer I, Hadar E, Hadden DR, Jovanovič L, Mestman JH, et al. (2013) Diabetes and Pregnancy: An Endocrine Society Clinical Practice Guideline. J Clin Endocrinol Metab 98(11): 4227-4249. 